\title{
THE PREVALENCE, CHARACTERISTICS, AND IMPACT OF WORK-RELATED MUSCULOSKELETAL DISORDERS AMONG PHYSICAL THERAPISTS IN THE KINGDOM OF SAUDI ARABIA - A CROSS-SECTIONAL STUDY
}

\author{
Venkata Nagaraj Kakaraparthi ${ }^{1,2}$, Karthik Vishwanathan ${ }^{3}$, Bhavana Gadhavi², Ravi Shankar Reddy ${ }^{1}$, \\ Paul Silvian Samuel ${ }^{1}$, Mastour Saeed Alshahrani ${ }^{1}$, Lalitha Kakaraparthi², Vamsi Krishna Gannamaneni ${ }^{4}$, \\ Jaya Shanker Tedla ${ }^{1}$ \\ ${ }^{1}$ King Khalid University, Abha, Saudi Arabia \\ College of Applied Medical Sciences, Department of Medical Rehabilitation Sciences \\ ${ }^{2}$ Parul University, Vadodara, Gujarat, India \\ Department of Physiotherapy \\ ${ }^{3}$ Parul University, Vadodara, Gujarat, India \\ Parul Sevashram Hospital, Parul Institute of Medical Sciences and Research, Department of Orthopaedics \\ ${ }^{4}$ Hail University, Hail, Saudi Arabia \\ College of Applied Medical Sciences, Department of Physiotherapy
}

\begin{abstract}
Background: Physical therapists are known to be susceptible to work-related musculoskeletal disorders (WMSDs), but the prevalence of WMSDs in Saudi Arabia has not been documented. This study aimed to establish the prevalence, characteristics, and risk factors of WMSDs among physical therapists in Saudi Arabia. Material and Methods: A cross-sectional study was conducted among 113 physical therapists in Saudi Arabia using a 6-component questionnaire. Descriptive statistics, incidence, percentages, and $\chi^{2}$ test were used for data analysis. Results: The response rate was $68.8 \%$. The reported 12 -month incidence of WMSDs was $83.8 \%$. The low back $(63.7 \%)$ was the most common site of these disorders, followed by the neck $(59.2 \%)$, while the hip/thigh (4.4\%) was the least involved body part. Incidence was related to gender: females were more affected than males (neck, shoulders, low back); age: younger therapists were more affected than older ones (shoulders, low back); working sector: government sector workers were more affected than those employed in other sectors (neck); and specialty: orthopedic specialists were the most frequently affected, followed by those specializing in neurology (thumbs, upper back, knees, ankle/foot). Most of the physical therapists had $>5$ periods of neck, shoulder, and low-back WMSDs. The most important risk factor for WMSDs was treating more patients in a day (47.7\%). The most frequently adopted handling strategy identified to combat WMSDS was modifying the patient's position (62.8\%). Conclusions: Overall, WMSDs among physical therapists in Saudi Arabia are common, with the low back and the neck constituting the most frequently affected body regions. Professional experience and the awareness of ergonomics principles can help prevent the early development of WMSDs among physical therapists. Med Pr. 2021;72(4):363-73
\end{abstract}

Key words: physical therapy, ergonomics, musculoskeletal disorders, workload, prevalence, Saudi Arabia

Corresponding author: Venkata Nagaraj Kakaraparthi, King Khalid University, College of Applied Medical Sciences, Department of Medical Rehabilitation Sciences, Abha, Saudi Arabia, e-mail: kvnagaraj13@yahoo.com Received: February 1, 2021, accepted: May 27, 2021

Funding: this work was supported by Deanship of Scientific Research, King Khalid University, Abha, Kingdom of Saudi Arabia (project No. RGP. 2/40/42 entitled "Prevalence of work-related musculoskeletal disorders among physical therapists," project manager: Ravi Shankar Reddy, Ph.D./Assist. Prof.). 


\section{INTRODUCTION}

Work-related musculoskeletal disorders (WMSDs) are among the leading health problems in physical therapists who are specifically facing a great risk [1]. The lifetime incidence of WRMDs among physical therapists has been stated to be $94 \%$ in Iran [2], $91.3 \%$ in Nigeria [3], 84.9\% in Egypt [4], 89\% in Greece [5], $53.5 \%$ in Spain [6], 47.6\% in Kuwait [7], 46\% in Bangladesh [8], and 55\% in Australia [9].

Physical therapists engage in repetitive lifting and managing loads, prolonged forced postures, and physically challenging tasks in their practices $[10,11]$. These activities are considered to constitute common causes of musculoskeletal pain, discomfort, and workplace absenteeism [12]. The quality of life can be adversely influenced, leading to reduced output and related health care expenses for both employees and employers [13]. The lifetime incidence of musculoskeletal pain in physical therapists ranges 53-91\%, with the low back being the most commonly affected body area [1].

Low-back pain is a widespread WMSD among physical therapists $[2,3,8,13,14]$ in the United Kingdom, reported at $68 \%$ [15]. In the USA, the incidence of lowback pain among physical therapists ranges $45-62 \%$ [13]. Mierzejewski et al. [16] found the frequency of low-back pain in Canada to be $49 \%$, while Shehab et al. [17] stated a $70 \%$ incidence of low-back complaints in Kuwait. Due to repeated overload on their spines, physical therapists in different countries rank after nurses with respect to work-related low-back pain among all health care practitioners [18]. The incidence of WMSDs in the low back was followed by those in the neck, wrist and hands, the upper back, and shoulders among physical therapists [1].

Research suggests that WMSDs among physical therapists may be associated with various risk factors: handling excessive physical loads, such as shifting and supporting patients [19]; treating a substantial number of patients in a single day [11]; working in a similar posture for lengthy periods [9]; performing identical tasks repeatedly [15]; maintaining awkward postures [20]; performing manual therapy techniques $[9,11]$; and working in a limited space $[11,17]$. However, in most studies, it does seem that patient handling and performing manual therapy techniques were constant risk factors which correlated with WMSDs among physical therapists. Along with this, the highest occurrence of WMSDs has been found in younger physical therapists $[11,15,16,19]$; female therapists report WMSDs more frequently than male therapists $[3,10,16,17,21]$; and differences in work settings influence the occurrence of those disorders [15,19,22,23].

Since these factors are broad and exceptional to physiotherapy, physical therapists in Saudi Arabia were anticipated to be a component of this representation despite the discrepancies in related practice settings. The authors believe that identifying these risk factors is necessary to help prevent WMSDs in physical therapists in the future. To the best of their knowledge, there has been little research about the occupational dangers of physiotherapy practice in Saudi Arabia. Consequently, a better investigation of these particular work-related risk factors is needed.

Hence, the aims of the present study were to:

investigate the prevalence of WMSDs and their association with demographic factors, work settings, and professional characteristics among physical therapists working in Saudi Arabia;

analyze the work factors that physical therapists identified as contributors to WMSDs;

avaluate the handling strategies used by physical therapists to combat WMSDs.

The results could contribute to a healthier work style and the development of efficient intervention strategies for preventing WMSDs among physical therapists.

\section{MATERIAL AND METHODS}

\section{Participants}

Physical therapists functioning in public or private sectors in different areas in Saudi Arabia participated in this cross-sectional study. The physical therapists who were registered in the Saudi Physical Therapy Association (SPTA) with $\geq 1$ year of work experience for $\geq 1 \mathrm{~h}$ /day in their present work setting were included in the study. The therapists who were elderly, retired, or non-practicing at the time of the study were excluded. The Ethics Committee of King Khalid University approved the present study protocol (ECM No. 2020-1602).

\section{Procedures}

The researchers contacted the physical therapists being members of the SPTA and invited them to participate voluntarily in the study. All the participants received a letter explaining the purpose of the study via electronic mail, along with the online questionnaire. The researchers described the questionnaire to every participant and gave a communication number should any additional clarification be required. Each subject gave consent 
to participate in this study by responding to the questionnaire. All the participants took approx. 15-20 min to complete the questionnaire. After a month of uploading the questionnaire online, the researchers sent a gentle reminder to all the participants inviting them to complete it if they had not done it previously. Incomplete questionnaires were excluded from the study.

\section{Questionnaire}

The questionnaire was mainly intended to collect data about self-reported musculoskeletal pain and work-related issues among the physical therapists. It was written in English, consisted of 6 components, and had been previously validated $[10,23,24]$. The first component of the questionnaire collected the demographic characteristics of the participants. The next component included questions concerning the participant's education, professional rank, professional experience, working hours, primary type of patients, working venues, areas of specialty, longest spell (in days), total number of episodes, nature of complaints, onset of complaints, type of treatment received for complaints, any expert that had been seen for the complaint, work position, and exercise habits. The subsequent questions were adopted from the Nordic Musculoskeletal Questionnaire [25], which was used to evaluate the participant's musculoskeletal complaints (pain or discomfort) in 9 anatomical regions by using a body diagram: 1) neck, 2) shoulders, 3) elbows, 4) hand/wrist, 5) upper back, 6) low back, 7) hips/thighs, 8) knees, and 9) ankle/foot.

In the next component, the period of WMSDs was evaluated using the following question: "How long does the pain or discomfort typically last?" The participants were instructed to select one of the following options: 1) $\leq 24 \mathrm{~h}$, 2) $24 \mathrm{~h}-1$ week, 3) 1 week-1 month, 4) 1-6 months, or 5) 6 months. The rate of occurrence of WMSDs was evaluated using the following question: "How many instances have you had this pain or discomfort?". For each area of the body, the participants were instructed to choose one of the following options: 1 ) once every 6 months or less, 2) once every 2-3 months, 3 ) once in a month, 4) once in a week, or 5) more than once a week. To evaluate the severity of the pain, a Visual Analogue Scale (VAS) which ranged from 0 (no pain) to 10 (the worst pain possible) was utilized for each body region. The next component of the questionnaire included the work factors that physical therapists recognized as contributing to WMSDs. The last component included handling strategies used by the physical therapists with WMSDs.
The SPSS software (SPSS version 21.0 for Windows; Inc, USA) was used to conduct statistical analyses. Descriptive statistics were used to estimate the incidence of WMSDs and demographic characteristics of the sample. Incidence rates and cross-tabulations were used to associate the occurrence of WMSDs with various demographic factors and work settings. Chi-square test was used to evaluate the relationship between the prevalence and association of WMSDs and demographic factors, work settings, and the professional characteristics among the physical therapists. The significance level was set at a $p$-value of $<0.05$ for all analyses.

\section{RESULTS}

\section{Response}

The questionnaires were completed by 125 (68.8\%) of the 183 qualified physical therapists invited to participate in the study. Of these, 12 questionnaires were not filled out completely and were, therefore, excluded from the analysis. Thus, the data from 113 participants were eventually used to evaluate the prevalence rates.

\section{Participants' description}

The characteristics for all subjects are presented in Table 1. The participants included $66(58.4 \%)$ males and $47(41.5 \%)$ females with a mean age of $30.3 \pm 5.6$ years and the body mass index (BMI) of $23.6 \pm 4.4 \mathrm{~kg} / \mathrm{m}^{2}$. The majority $(55.7 \%)$ of the physical therapists were working in a government hospital. Orthopedics was the most frequent area of specialty, followed by neurology, pediatrics, and other specialties. Overall, $47 \%$ of the physical therapists worked $>40 \mathrm{~h} /$ week, and the majority $(67 \%)$ were in a permanent job (Table 1).

\section{Prevalence}

The majority of the physical therapists $(83.8 \%)$ complained of experiencing WMSDs during 12 months before the study. The 12-month incidence of WMSDs in various parts of the body, compared to previous studies findings, are represented in Table 2. The low-back region was the most common location of those disorders (63.7\%) while the hips/thighs $(4.4 \%)$ were the least affected body part (Table 2).

\section{Association of WMSDs with demographic factors, work settings, and professional characteristics of physical therapists}

The incidence of work-related neck and low-back complaints was considerably correlated with gender, with 
Table 1. Demographics and professional characteristics of the participants (physical therapists, Saudi Arabia, 2021)

\begin{tabular}{cc}
\hline \multirow{2}{*}{ Variable } & \multicolumn{2}{c}{$\begin{array}{c}\text { Participants } \\
(\mathrm{N}=113)\end{array}$} \\
\cline { 2 - 3 } & $\mathrm{n} \quad \%$ \\
\hline
\end{tabular}

\section{Gender}

male

female

Age

$$
\begin{aligned}
& 20-30 \text { years } \\
& 31-40 \text { years } \\
& 41-50 \text { years }
\end{aligned}
$$

Education

$$
\begin{aligned}
& \text { bachelor's degree } \\
& \text { master's degree } \\
& \text { doctoral degree }
\end{aligned}
$$$$
\text { Smoking }
$$$$
\text { yes }
$$$$
\text { no }
$$

Professional rank

$$
\text { junior physical therapist }
$$

physical therapist

senior physical therapist

physiotherapy specialist

head of the department

Working sector

government sector

private sector

both government and private sectors

specialized hospital

schools

Areas of specialty

orthopedics

neurology

cardiology

burns

geriatrics

pediatrics

sports

others

Work experience

$0-5$ years
Table 1. Demographics and professional characteristics of the participants (physical therapists, Saudi Arabia, 2021) - cont.

\begin{tabular}{c} 
Variable \\
Participants \\
\cline { 2 - 3 }$(\mathrm{N}=113)$ \\
$\mathrm{n} \quad \%$
\end{tabular}

Work experience - cont.

$11-15$ years

$>15$ years

Working time

$\leq 10 \mathrm{~h} /$ week

11-20 h/week

21-30 h/week

31-40 h/week

$>40$ h/week

Working position

standing

sitting

standing and sitting

Patients seen

$\leq 30 /$ week
$31-50 /$ week
$>50 /$ week

ype of employment

permanent

contract

self-employed

Physical activity

$0 \mathrm{~min} /$ week

1-15 $\mathrm{min} /$ week

16-30 $\mathrm{min} /$ week

31-45 $\mathrm{min} /$ week

46-60 $\mathrm{min} /$ week

61-90 $\mathrm{min} /$ week

$>90 \mathrm{~min} /$ week

Any other work along with physiotherapy

$\begin{array}{lcc}\text { yes } & 21 & 18.5 \\ \text { no } & 92 & 81.4\end{array}$

more females than males reporting these complaints. In the same way, work-related shoulder and low-back complaints were correlated with the age of the participants and occurred more frequently in younger age groups. Work-related complaints of the neck were associated with working sectors and working position. 
Table 2. Comparison of 12-month prevalence of work-related musculoskeletal disorders (WMSDs) by body part among physical therapists from different countries

\begin{tabular}{|c|c|c|c|c|c|c|c|c|c|c|}
\hline \multirow[b]{2}{*}{ Reference } & \multicolumn{10}{|c|}{$\begin{array}{c}\text { Body areas } \\
{[\%]}\end{array}$} \\
\hline & $\begin{array}{l}\text { low back } \\
(\mathrm{N}=72)\end{array}$ & $\begin{array}{c}\text { neck } \\
(\mathrm{N}=67)\end{array}$ & $\begin{array}{l}\text { shoulder } \\
(\mathrm{N}=46)\end{array}$ & $\begin{array}{c}\text { wrists/ } \\
\text { hand } \\
(\mathrm{N}=27)\end{array}$ & $\begin{array}{c}\text { upper } \\
\text { back } \\
(\mathrm{N}=22)\end{array}$ & $\begin{array}{c}\text { knees } \\
(\mathrm{N}=16)\end{array}$ & $\begin{array}{l}\text { thumbs } \\
(\mathrm{N}=15)\end{array}$ & $\begin{array}{l}\text { elbow/ } \\
\text { forearm } \\
(\mathrm{N}=12)\end{array}$ & $\begin{array}{c}\text { ankle/ } \\
\text { foot } \\
(\mathrm{N}=9)\end{array}$ & $\begin{array}{l}\text { hip/thigh } \\
(\mathrm{N}=5)\end{array}$ \\
\hline $\begin{array}{l}\text { Venkata et al., 2021, } \\
\text { Saudi Arabia [this article] }\end{array}$ & 63.7 & 59.2 & 40.7 & 23.8 & 20.3 & 14.1 & 13.2 & 10.6 & 7.9 & 4.4 \\
\hline $\begin{array}{l}\text { Glover et al., 2005, } \\
\text { United Kingdom [15] }\end{array}$ & 37.2 & 25.7 & 14.8 & 12.5 & 18.4 & 7.8 & 17.8 & 5.5 & 4.1 & 4.8 \\
\hline West et al., 2001, Australia [9] & 22.0 & 20.0 & 10.0 & 14.0 & 11.0 & 3.0 & - & 3.3 & 2.0 & 3.0 \\
\hline
\end{tabular}

All these correlations were statistically significant $(\mathrm{p}<0.001)$ (Table 3$)$.

\section{Characteristics of WMSDs}

Most of the physical therapists in Saudi Arabia had 2-5 periods of WMSDs of the neck, shoulders, elbow/ forearm, wrist/hand, thumbs, upper back, low back, and ankle/feet (Table 4).

Pain was an extremely frequent complaint followed by spasm, stiffness, and other symptoms. In relation to treatment received, most participants who had neck, shoulder, elbow, upper-back, low-back, and ankle/foot complaints received physical therapy treatment (Table 4).

\section{Work factors}

The physical therapists with WMSDs were asked to consider 16 work components that had been recognized by earlier studies [26,27] and to specify which factors had contributed to their WMSDs. The 2 most vital work factors frequently identified by the physical therapists surveyed were handling many patients daily $(47.7 \%)$ and functioning in the same situation for extended periods (43.3\%). Irregular work schedules (3.5\%) and working with psychological/confused patients $(1.7 \%)$ were mentioned as the most insignificant factors (Table 5).

\section{Handling strategies}

The most frequent handling strategies adopted by the physical therapists were modifying the patients position (62.8\%) and adjusting their positions during treatment $(51.3 \%)$. Lastly, the least implemented handling strategies were warming up and stretching before starting treatment (7.9\%), and using electrotherapy modalities instead of manual techniques (5.3\%) (Table 6).

\section{DISCUSSION}

This study aimed to evaluate the prevalence of WMSDs and the handling strategies utilized to combat these disorders among physical therapists working in Saudi Arabia. The results showed that $83.8 \%$ of the physical therapists were affected by WMSDs. Most of the physical therapists affected with WMSDs were aged 20-40 years, with more male than female physical therapists. Moreover, the physical therapists in Saudi Arabia were helping treat a significant number of patients in a day, functioning in a similar position for a long time, and performing lifting tasks vigorously. Previous studies have linked performing joint mobilization techniques, low job control, and high psychosocial demands to WMSDs among physical therapists $[10,11,28]$. This prevalence was less than the incidence reported in Nigeria (91.3\%) [3] and Australia (91\%) [11], but higher than that reported in the United Kingdom (74\%) [15], the USA (80\%) [10], and Turkey (59\%) [29]. The possible reasons for these variations are differences in research populations, sample size, gender distribution, understaffing, and differences in practice between different studies $[3,11,15]$.

In the present study, low back was stated as the persistent site of WMSDs among physical therapists in Saudi Arabia, with a 12 -month incidence rate of $63.7 \%$. This result is consistent with that described in previous studies $[3,9,10,15,23]$. The incidence of low-back WMSDs was followed by neck, shoulders, wrist/hand, knee, thumbs, ankle/foot, and hip/thigh complaints, which contrasts with the findings of previous studies $[3,15]$. The 12-month incidence rates in the neck, shoulder, and wrist/hand complaints were higher than in previous studies $[3,9,15]$, and knee, thumbs, 


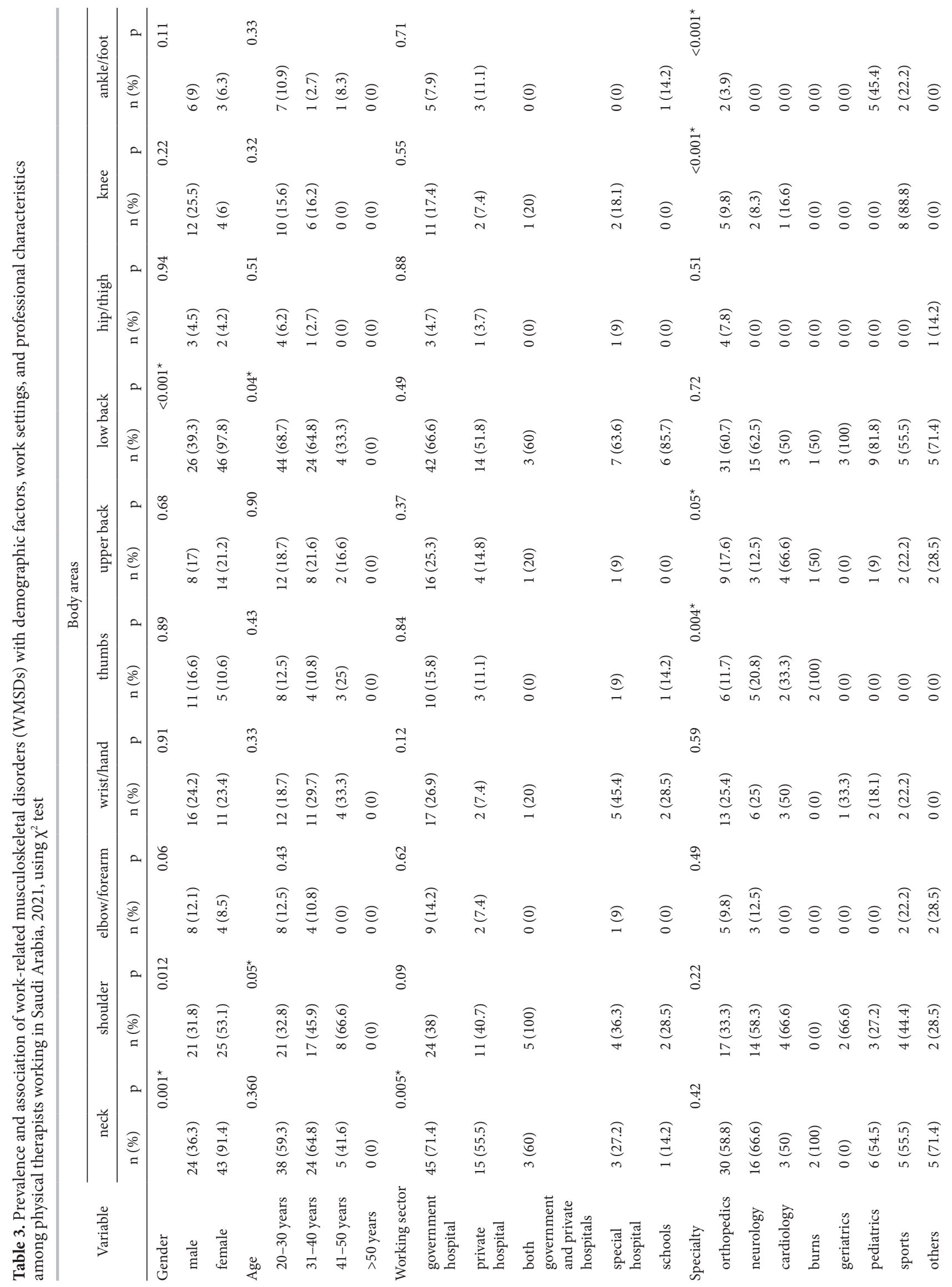




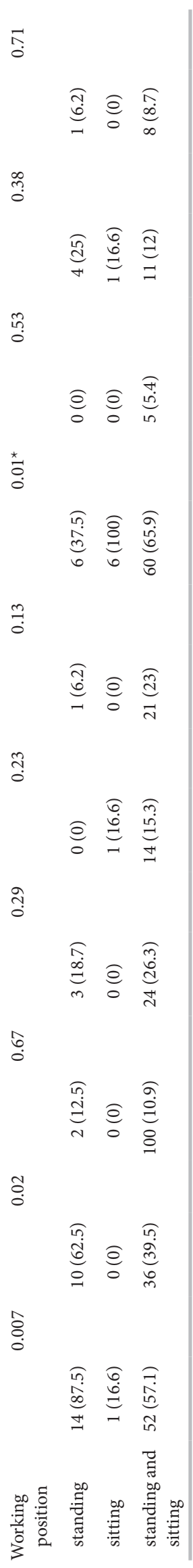

ankle/foot, and hip/thigh complaints were lower than the findings from Nigeria, the United Kingdom, and Sweden $[3,15,28]$. These results can be an additional replication of the complete representation of work settings and working conditions of practice, which may cause the high incidence of WMSDs in these anatomical regions among physical therapists in Saudi Arabia.

With regard to gender, the authors observed a significantly greater incidence of neck $(91.4 \%)$, shoulder (53.1\%), and low-back (97.8\%) complaints among female physical therapists than among male therapists, which was $36.3 \%, 31.8 \%$, and $39.3 \%$, respectively. This result is consistent with those described in previous studies $[10,15,29]$. Gender is believed to be a potential risk factor for developing WMSDs in these areas because of differences in body weight, height, muscle strength, and body composition $[10,15]$. These factors create a disadvantage for female therapists, especially when lifting dependent patients, transferring patients, treating many patients in a day, and carrying heavy equipment, which places an additional load on the body.

However, in the present study, the authors noticed a higher frequency $(21.2 \%)$ of upper-back complaints among female physical therapists; this result may be related to bending/twisting for a long time, working in an unchanged position for extended periods, and working in an awkward position. The male physical therapists had more elbow, wrist/hand, and thumb complaints than the female therapists, in contrast with previous studies $[3,10]$. The authors believe this discrepancy was due to the more frequent use of manual therapy techniques by male therapists.

The results of the present study show that participants' age had a significant $(\mathrm{p}<0.001)$ correlation with shoulder and low-back complaints, especially in younger physical therapists, which is inconsistent with previous studies $[10,11]$. This explanation was mainly due to inexperience, working $>40 \mathrm{~h} /$ week, lack of skills, and frequently working in orthopedic and neurology rehabilitation departments [16]. The authors also found that physical therapists aged 41-50 years had fewer WMSDs than younger therapists as they shift into less physically challenging work, mostly into administration positions [10].

However, only the incidence of neck WMSDs was significantly $(\mathrm{p}<0.001)$ associated with the working sector, in contrast with previous studies $[7,10]$. A possible justification of these results could be the work style of physical therapy practice in Saudi Arabia, as physical therapists 


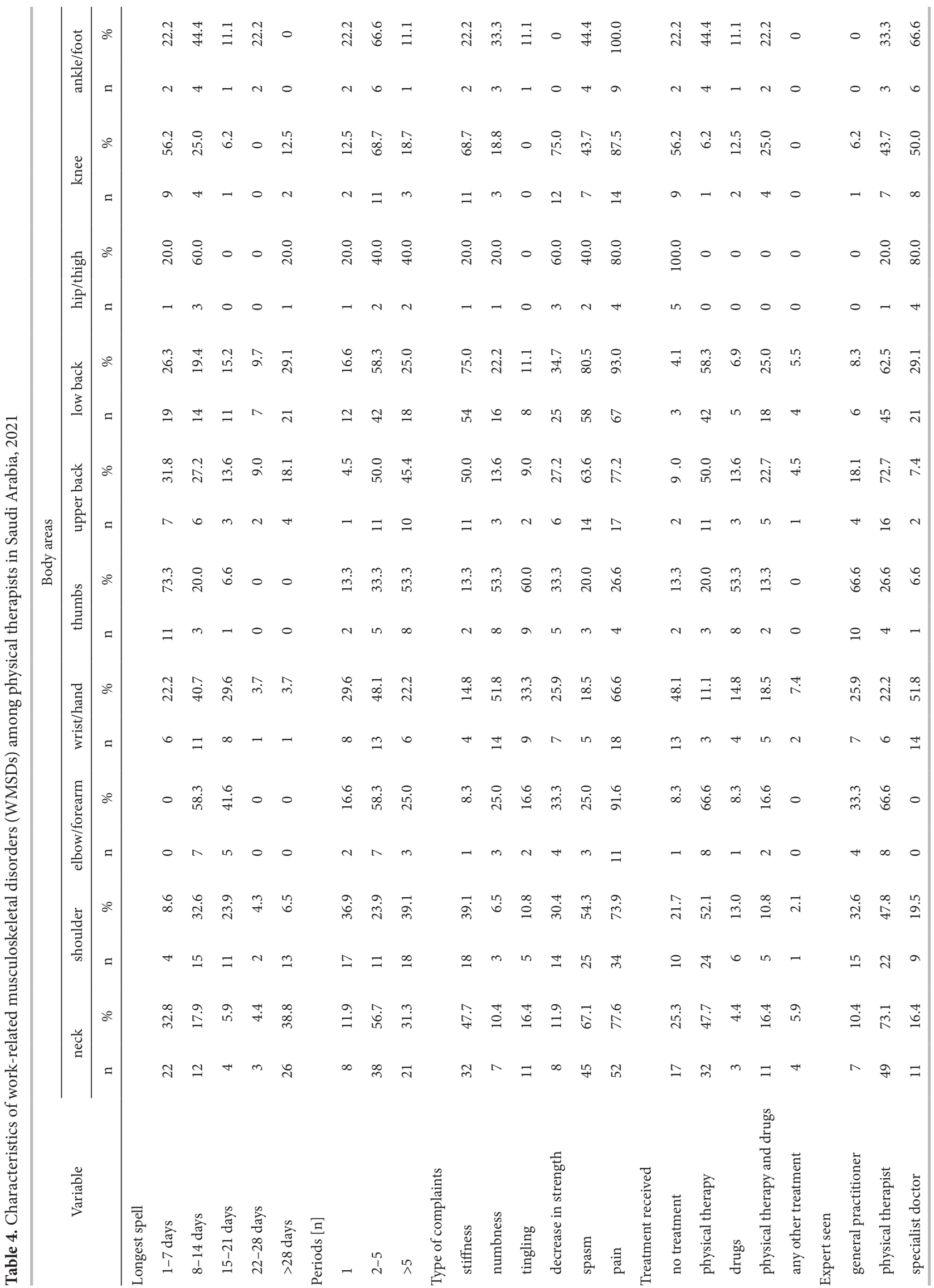


Table 5. Risk factors that physical therapists identified as contributors to work-related musculoskeletal disorders (WMSDs) (physical therapists, Saudi Arabia, 2021)

\begin{tabular}{|c|c|c|}
\hline \multirow[t]{2}{*}{ Risk factor } & \multicolumn{2}{|c|}{$\begin{array}{c}\text { Participants } \\
(\mathrm{N}=113)\end{array}$} \\
\hline & $\mathrm{n}$ & $\%$ \\
\hline Treating more patients in a day & 54 & 47.7 \\
\hline Working in the same position & 49 & 43.3 \\
\hline Lifting the patients & 46 & 40.7 \\
\hline Working in an awkward position & 37 & 32.7 \\
\hline Transferring the patients & 26 & 23.0 \\
\hline Performing manual therapy techniques & 22 & 19.4 \\
\hline Bending/twisting for a long time & 19 & 16.8 \\
\hline Assisting patients during gait activities & 18 & 15.9 \\
\hline Carrying/lifting heavy weights & 15 & 13.2 \\
\hline Sudden movement/fall by patients & 11 & 9.7 \\
\hline No proper rest during work time & 9 & 7.9 \\
\hline Inadequate training in injury prevention & 7 & 6.1 \\
\hline Continuing work when injured & 7 & 6.1 \\
\hline Working away from the body & 5 & 4.4 \\
\hline Irregular work schedule & 4 & 3.5 \\
\hline Working with psychological/confused patients & 2 & 1.7 \\
\hline
\end{tabular}

working in the government sector tend to work overtime without enough rest breaks, work irregular shifts, and perform the same task repeatedly. Alternating work between government and private hospitals would allow therapists to take regular breaks with less working time, which is essential in preventing WMSDs. No association was found between the prevalence of low-back WMSDs and any particular specialty area.

These results suggest that working in both standing and sitting positions increases the likelihood of developing WMSDs, especially in the low back. This contrasts with previous findings among common working populations, which indicated that these correlations could be due to constant static overload on the musculoskeletal system [30].

In the present study, the majority of the physical therapists identified different risk factors as contributing to the incidence of WMSDs in the increasing order of prominence: transferring patients, working in an awkward position, lifting patients, working in the same position, and treating a significant number of patients in a day. This result is consistent with that described in previous studies [9-11]. The tasks of lifting and transferring patients were associated with the development of low-back WMSDs, and workload issues were related to the complaints in the neck, shoulder, elbow/forearm, wrist/hand, thumbs, and upper back. However, given that physical therapists self-recognized the influencing risk factors, the correlation may be due to bias and what the physical therapists assumed to be genuine, rather than the factors actually producing their injuries. These conclusions should thus be regarded cautiously until they are individually verified.

Lastly, the most frequently adopted handling strategies the physical therapists used to combat WMSDs were changing their place or the patient's position, choosing the skills that would not increase their pain or discomfort, and altering bed height during treatment. This was similar to findings in a previous study [15].

Table 6. Handling strategies used by physical therapists to combat work-related musculoskeletal disorders (WMSDs) (physical therapists, Saudi Arabia, 2021)

\begin{tabular}{|c|c|c|c|c|c|c|}
\hline \multirow{3}{*}{ Strategy } & \multicolumn{6}{|c|}{ Occurrence } \\
\hline & \multicolumn{2}{|c|}{ almost } & \multicolumn{2}{|c|}{ sometimes } & \multicolumn{2}{|c|}{ never } \\
\hline & $\mathrm{n}$ & $\%$ & $\mathrm{n}$ & $\%$ & $\mathrm{n}$ & $\%$ \\
\hline I modify patient's position during treatment & 71 & 62.8 & 33 & 29.2 & 9 & 7.9 \\
\hline I modify my position during treatment & 58 & 51.3 & 42 & 37.1 & 13 & 11.5 \\
\hline I select techniques that do not increase my discomfort & 37 & 32.7 & 30 & 26.5 & 46 & 40.7 \\
\hline I adjust bed height before starting the treatment & 25 & 22.1 & 54 & 47.7 & 34 & 30.0 \\
\hline I stop treatment if anything increases my discomfort & 18 & 15.9 & 38 & 33.6 & 57 & 50.4 \\
\hline I halt repeatedly so that I can stretch and alter my position & 13 & 11.5 & 61 & 53.9 & 39 & 34.5 \\
\hline I get someone help me to handle the patient during treatment & 12 & 10.6 & 59 & 52.2 & 42 & 37.1 \\
\hline I warm up and stretch before beginning the manual techniques & 9 & 7.9 & 26 & 23.0 & 78 & 69.0 \\
\hline I practice electrotherapy as a substitute for manual therapy techniques & 6 & 5.3 & 57 & 50.4 & 50 & 44.2 \\
\hline
\end{tabular}


Furthermore, most physical therapists in this study paused treatment regularly to stretch, change their position, and get help from someone else when handling the patient during treatment. Only $5.3 \%$ of the physical therapists in this study utilized the option of electrotherapy modalities instead of manual therapy techniques to prevent injury, stating that they used this strategy to safeguard themselves.

\section{Limitations}

The present study has some limitations. First, it was a cross-sectional study where the familiar interpretations cannot be derived from the results. Second, the study depends on self-reported data, so there is a likelihood that the participants tended to over- or underestimate their exposure. Third, the study did not assess the association between WMSDs and the psychosocial factors of the physical therapists.

\section{CONCLUSIONS}

The results of this study reveal that the 12-month prevalence of WMSDs among physical therapists in Saudi Arabia was high. The most affected location was the low back, followed by the neck region. The physical therapists working in the government sector were significantly affected by WMSDs, especially in the neck region. Regarding the specialty area, the physical therapists who were working in the neurology specialty displayed a significant percentage of WMSDs followed by those specializing in orthopedics. These findings emphasize the necessity of developing training programs on ergonomics and efficient interventions to limit WMSDs and improve working situations among physical therapists in Saudi Arabia.

\section{ACKNOWLEDGEMENTS}

The authors would like to sincerely thank the subjects who participated in their study, especially during this pandemic.

\section{REFERENCES}

1. Vieira ER, Schneider P, Guidera C, Gadotti IC, Brunt D. Work-related musculoskeletal disorders among physical therapists: a systematic review. J Back Musculoskelet Rehabil. 2016;29(3):417-28, https://doi.org/10.3233/BMR150649.

2. Rahimi F, Kazemi K, Zahednejad S, López-López D, CalvoLobo C. Prevalence of work-related musculoskeletal disorders in Iranian physical therapists: a cross-sectional study.
J Manipulative Physiol Ther. 2018 Jul-Aug;41(6):503-07, https://doi.org/10.1016/j.jmpt.2018.02.003.

3. Adegoke BO, Akodu AK, Oyeyemi AL. Work-related musculoskeletal disorders among Nigerian physiotherapists. BMC Musculoskelet Disord. 2008;9:112, https://doi. org/10.1186/1471-2474-9-112.

4. Atia DT, Abdelazeim FH, Radwan H. Impact of work-related musculoskeletal disorders on Egyptian pediatric physical therapists: one-year follow-up study. Trends Appl Sci Research. 2015;10:175, https://doi.org/10.1186/14712474-9-112.

5. Anyfantis I, Biska A. Musculoskeletal disorders among Greek physiotherapists: traditional and emerging risk factors. Saf Health Work. 2018 Sep;9(3):314-8, https://doi. org/10.1016/j.shaw.2017.09.003.

6. Ezzatvar Y, Calatayud J, Andersen LL, Aiguadé R, Benítez J, Casaña J. Professional experience, work setting, work posture and workload influence the risk for musculoskeletal pain among physical therapists: a cross-sectional study. Int Arch Occup Environ Health. 2020 Feb;93(2):189-96, https://doi.org/10.1007/s00420-019-01468-7.

7. Alrowayeh HN, Alshatti TA, Aljadi SH, Fares M, Alshamire MM, Alwazan SS. Prevalence, characteristics, and impacts of work-related musculoskeletal disorders: a survey among physical therapists in the State of Kuwait. BMC Musculoskelet Disord. 2010 Jun 11;11:116, https:// doi.org/10.1186/1471-2474-11-116.

8. Mondal A, Mehedi MMH (2019) Work Related Musculoskeletal Disorders among Physiotherapists in Dhaka City. Bone Muscle 2:001-004.

9. West DJ, Gardner D. Occupational injuries of physiotherapists in North and Central Queensland. Aust J Physiother. 2001;47(3):179-86, https://doi.org/10.1016/ s0004-514(14)60265-8.

10. Bork BE, Cook TM, Rosecrance JC, Engelhardt KA, Thomason M-EJ, Wauford IJ, et al. Work-related musculoskeletal disorders among physical therapists. Phys Ther. 1996 Aug;76(8):827-35, https://doi.org/10.1093/ptj/76.8.827.

11. Cromie JE, Robertson VJ, Best MO. Work-related musculoskeletal disorders in physical therapists: prevalence, severity, risks, and responses. Phys Ther. 2000 Apr;80(4): 336-51, https://doi.org/10.1093/ptj/80.4.336.

12. Luger T, Maher CG, Rieger MA, Steinhilber B. Workbreak schedules for preventing musculoskeletal disorders in workers-a Cochrane review. Cochrane Database Syst Rev. 2019 Jul 23;7(7):CD012886, https://doi.org/10.1002/ 14651858 .

13. Bhattacharya A. Costs of occupational musculoskeletal disorders (MSDs) in the United States. 2014;44:448-54, https://doi.org/10.1016/j.ergon.2014.01.008. 
14. Iqbal Z, Alghadir A. Prevalence of work-related musculoskeletal disorders among physical therapists. Med Pr. 2015;66(4):459-69, https://doi.org/10.13075/mp.5893. 00142 .

15. Glover W, McGregor A, Sullivan C, Hague J. Work-related musculoskeletal disorders affecting members of the Chartered Society of Physiotherapy. Physiotherapy. 2005;91: 138-47, https://doi.org/10.1016/j.physio.2005.06.001.

16. Mierzejewski M, Kumar S. Prevalence of low back pain among physical therapists in Edmonton, Canada. Disabil Rehabil. 1997 Aug;19(8):309-17, https://doi.org/ 10.3109/09638289709166544.

17. Shehab D, Al-Jarallah K, Moussa MA, Adham N. Prevalence of low back pain among physical therapists in Kuwait. Med Princ Pract. 2003 Oct-Dec;12(4):224-30, https://doi.org/10.1159/000072288.

18. Hollingdale R, Warin J. Back pain in nursing and associated factors: a study. Nurs Stand. 1997 Jun 18;11(39):35-8, https://doi.org/10.7748/ns1997.06.11.39.35.c2460.

19. Holder NL, Clark HA, DiBlasio JM, Hughes CL, Scherpf JW, Harding L, et al. Cause, prevalence, and response to occupational musculoskeletal injuries reported by physical therapists and physical therapist assistants. Phys Ther. 1999 Jul;79(7):642-52, https://doi.org/10.1093/ptj/79.7.642.

20. Rosecrance JC, Cook TM. Upper extremity musculoskeletal disorders: occupational association and a model for prevention. Centr Eur J Occup Environ Med 1998;4:214-31.

21. Darragh AR, Huddleston W, King P. Work-related musculoskeletal injuries and disorders among occupational and physical therapists. Am J Occup Ther. May-Jun 2009;63(3):351-62, https://doi.org/10.5014/ajot.63.3.351.

22. Rozenfeld V, Ribak J, Danziger J, Tsamir J, Carmeli E. Prevalence, risk factors and preventive strategies in workrelated musculoskeletal disorders among Israeli physical therapists. Physiother Res Int. 2010 Sep;15(3):176-84, https://doi.org/10.1002/pri.440.
23. Salik Y, Özcan A. Work-related musculoskeletal disorders: a survey of physical therapists in Izmir-Turkey. BMC Musculoskelet Disord. 2004 Aug 18;5:27, https:// doi.org/10.1186/1471-2474-5-27.

24. Nordin NAM, Leonard JH, Thye NC. Work-related injuries among physiotherapists in public hospitals: a Southeast Asian picture. Clinics (Sao Paulo). 2011;66(3):373-8, https://doi.org/10.1590/s1807-59322011000300002.

25. Kuorinka I, Jonsson B, Kilbom A, Vinterberg H, BieringSørensen F, Andersson G, et al. Standardised Nordic questionnaires for the analysis of musculoskeletal symptoms. Appl Ergon. 1987 Sep;18(3):233-7, https://doi.org/ 10.1016/0003-6870(87)90010-x.

26. Lotters F, Burdorf A, Kuiper J, Miedema H. Model for the work-relatedness of low-back pain. Scand J Work Environ Health. 2003 Dec;29(6):431-40, https://doi.org/ 10.5271/sjweh.749.

27. Palmer KT, Smedley J. Work relatedness of chronic neck pain with physical findings-a systematic review. Scand J Work Environ Health. 2007 Jun;33(3):165-91, https:// doi.org/10.5271/sjweh.1134.

28. Wilhelmus Johannes Andreas G, Wernstedt P, Campo M. Work-related musculoskeletal disorders in female Swedish physical therapists with more than 15 years of job experience: prevalence and associations with work exposures. Physiother Theory Pract. 2011 Apr;27(3):213-22, https://doi.org/10.3109/09593985.2010.481323.

29. Salik Y, Ozcan A. Work-related musculoskeletal disorders: a survey of physical therapists in Izmir-Turkey. BMC Musculoskelet Disord. 2004 Aug 18;5:27, https://doi.org/ 10.1186/1471-2474-5-27.

30. Andersen JH, Haahr JP, Frost P. Risk factors for more severe regional musculoskeletal symptoms: a two-year prospective study of a general working population. Arthritis Rheum. 2007 Apr;56(4):1355-64, https://doi.org/10.1002/ art.22513.

This work is available in Open Access model and licensed under a Creative Commons Attribution-NonCommercial 3.0 Poland License - http://creativecommons.org/licenses/by-nc/3.0/pl/deed.en. 